\title{
Ether-water partitioning and permeability through nude mouse skin in vitro. II. Hydrocortisone $21-n$-alkyl esters, alkanols and hydrophilic compounds
}

\author{
Chrisita Ackermann ${ }^{1}$, G.L. Flynn ${ }^{2}$ and W.M. Smith ${ }^{2}$ \\ ${ }^{\prime}$ Department of Pharmaceutics, Potchefstroom University for Christian Higher Education, Potchefstroom (South Africa) \\ and ${ }^{2}$ College of Pharmacy, University of Michigan, Ann Arbor, MI 48109 (U.S.A.) \\ (Received 20 September 1985) \\ (Modified version received 9 October 1986) \\ (Accepted 7 November 1986)
}

Key words: Hydrocortisone; Alkanol; Urea; Skin; Permeability; Ether-water; Partitioning

\section{Summary}

The permeability coefficients obtained by means of an infinite dose diffusion cell system with nude mouse skin in vitro were compared to the ether-water partition coefficients of the following compounds: glucose, urea, glycerol, thiourea, alkanols (methanol to octanol), hydrocortisone and hydrocortisone $21-n$-alkyl esters (-acetate to -heptanoate). The permeability coefficients ranged from $1.0 \times 10^{-6} \mathrm{~cm} / \mathrm{h}$ (glucose) to $0.34 \mathrm{~cm} / \mathrm{h}$ (hydrocortisone-21-heptanoate). The ether-water partition coefficients ranged between $9.0 \times 10^{-6}$ (glucose) and $1.4 \times 10^{4}$ (hydrocortisone-21-heptanoate). No general pattern emerged when the permeability coefficient is taken as a function of the ether-water partition coefficient for these compounds. Therefore the skin can not be regarded as a simple lipoidal barrier.

\section{Introduction}

The skin has been regarded as a simple lipoidal barrier by Treherne (1956), Scheuplein and Blank (1973) and Dürrheim (1977) to various compounds. It can therefore be expected that the ether-water partition coefficients could be used to model the partitioning of compounds into the lipid phase of the skin. The objective when comparing the permeability coefficients of compounds ranging widely in hydrophobicity to their etherwater partition coefficients is to see whether a pattern emerges which can be used as a guide to

Correspondence: C. Ackermann, Department of Pharmaceutics, Potchefstroom University for Christian Higher Education, Potchefstroom 2520, South Africa. the possible mechanisms by which these compounds traverse the skin and particularly the stratum corneum. If that could be done, the etherwater partition coefficient of a compound can be used as a parameter to estimate its permeability coefficient through the skin.

The compounds used in this study, their permeability coefficients and ether-water partition coefficients are listed in Table 1.

The ether-water partition coefficients of hydrocortisone were reported by Katz and Shaikh (1965), Nathansohn et al. (1969) and Flynn (1971), those of hydrocortisone-21-acetate by Katz and Shaikh (1965), Mantica et al. (1970) and Flynn (1971) and those of hydrocortisone-21-butyrate and hydrocortisone-21-hexanoate only by Flynn (1971).

The values found by the different workers dif- 
fer substantially and except for hydrocortisone and hydrocortisone-21-acetate the data on the ether-water partition coefficients of the other hydrocortisone 21-n-alkyl esters were only assessed by Flynn (1971).

The ether-water partition coefficients were determined to supplement the information available in the literature and to verify the values found by previous workers. The ether-water partition coefficients of hydrocortisone and a series of $21-n$-alkyl esters were determined by means of a HPLC method. This method obviated concerns of impurity of the compounds as it is molecularly specific.

\section{Materials and Methods}

The materials and methods for the determination of the permeability coefficients and etherwater partition coefficients of all the compounds mentioned in this study, had been described previously as indicated in Table 1. All the permeability coefficients were obtained by means of an infinite dose diffusion cell system with nude mouse skin (SKH-hr-1 strain) in vitro. Only the determination of the ether-water partition coefficients of hydrocortisone and the hydrocortisone-21-n-alkyl esters will be described here.

Hydrocortisone was obtained from the Upjohn Company and was used without further purification. The hydrocortisone 21-n-alkyl esters (acetate through to heptanoate) were synthesised as outlined by Hagen (1979) and Smith (1982) by reacting an excess of the anhydride of a specific acid with $5 \mathrm{~g}$ of hydrocortisone in $100 \mathrm{ml}$ of pyridine.

Double-distilled water and analytical reagent ether were used to prepare the cosaturated phases. Water and ether were added to a 2-litre separator and shaken to obtain cosaturation of the phases. The separator was set aside for $24 \mathrm{~h}$ to allow for temperature and further phase equilibrium. All remaining steps were carried out at room temperature $\left(23 \pm 1^{\circ} \mathrm{C}\right)$. An appropriate amount of steroid (1-10 mg, depending on the steroid) was accurately weighed and put into a $50 \mathrm{ml}$ conical flask. This was dissolved in the ether phase, which was maintained at approximately $25-50 \mathrm{ml}$. An ap-

\section{TABLE 1}

Permeability coefficients and ether-water partition coefficients of glucose, urea, glycerol and thiourea, a homologous series of alkanols and hydrocortisone and its $21-n$-alkyl esters

\begin{tabular}{|c|c|c|}
\hline Compound & $\begin{array}{l}\text { Permeability } \\
\text { coefficient } \\
(\mathrm{cm} / \mathrm{h})\end{array}$ & $\begin{array}{l}\text { Ether-wate } \\
\text { partition } \\
\text { coefficient }\end{array}$ \\
\hline Glucose & $9.5 \times 10^{-5} \mathrm{a}$ & $8.7 \times 10^{-6}$ \\
\hline Urea & $1.2 \times 10^{-4} \mathrm{a}$ & $3.2 \times 10^{-4} \mathrm{a}$ \\
\hline Glycerol & $1.4 \times 10^{-4} \mathrm{a}$ & $5.1 \times 10^{-4}$ \\
\hline Thiourea & $9.6 \times 10^{-5} \mathrm{a}$ & $7.3 \times 10^{-3}$ \\
\hline Methanol & $2.6 \times 10^{-3} \mathrm{~b}$ & $9.6 \times 10^{-2}$ \\
\hline Ethanol & $4.8 \times 10^{-3} b$ & $2.8 \times 10^{-1}$ \\
\hline Propanol & $5.4 \times 10^{-3} \mathrm{~b}$ & $9.4 \times 10^{-1}$ \\
\hline Butanol & $1.5 \times 10^{-2} \mathrm{~b}$ & 5.9 \\
\hline Pentanol & $2.2 \times 10^{-2} \mathrm{~b}$ & $1.6 \times 10^{1}$ \\
\hline Hexanol & $4.8 \times 10^{-2} b$ & $6.3 \times 10^{1}$ \\
\hline Heptanol & $9.3 \times 10^{-2} \mathrm{~b}$ & $2.4 \times 10^{2}$ \\
\hline Octanol & $9.7 \times 10^{-2} \mathrm{~b}$ & $8.9 \times 10^{2}$ \\
\hline Hydrocortisone & $1.6 \times 10^{-4} \mathrm{e}$ & 1.4 \\
\hline Hydrocortisone-21-acetate & $1.7 \times 10^{-3} \mathrm{e}$ & $2.7 \times 10^{1}$ \\
\hline Hydrocortisone-21-propionate & $9.8 \times 10^{-3} \mathrm{e}$ & $9.5 \times 10^{1}$ \\
\hline Hydrocortisone-21-butyrate & $4.3 \times 10^{-2} \mathrm{e}$ & $3.0 \times 10^{2}$ \\
\hline Hydrocortisone-21-pentanoate & $7.1 \times 10^{-2} \mathrm{e}$ & $9.1 \times 10^{2}$ \\
\hline Hydrocortisone-21-hexanoate & $2.0 \times 10^{-1} \mathrm{e}$ & $4.1 \times 10^{3}$ \\
\hline Hydrocortisone-21-heptanoate & $3.4 \times 10^{-1} \mathrm{e}$ & $1.4 \times 10^{4}$ \\
\hline
\end{tabular}

Also see Fig. 2. a, Taken from Ackermann (1983); b, taken from Dürrheim (1977); c, taken from Hansch and Leo (1979); $\mathrm{d}$, calculated from the literature values mentioned under c; e, taken from Smith (1982) - values obtained without the enzyme inhibitor; $f$, this study.

propriate amount of water phase $(25-500 \mathrm{ml} \mathrm{de}-$ pending on the solubility of steroid) was placed in an appropriately sized separator $(60-1000 \mathrm{ml})$. The steroid solution in the ether phase was added with no attempt to rinse any residual steroid from the flask or funnel used. The phases were shaken intermittently, allowing sufficient time between agitations for the phases to reform.

The system was allowed to stand for 20 to 30 minutes to assure complete phase separation. Then the aqueous phase was transferred to a clean, appropriately sized separator with great care taken to assure that no ether phase contaminated it at this point. The ether phase was immediately transferred to a $100-\mathrm{ml}$ round bottom flask, the phase weight was recorded and the phase was evaporated to dryness on a Buchi evaporator. The aqueous phase was extracted with four $25-\mathrm{ml}$ portions of 


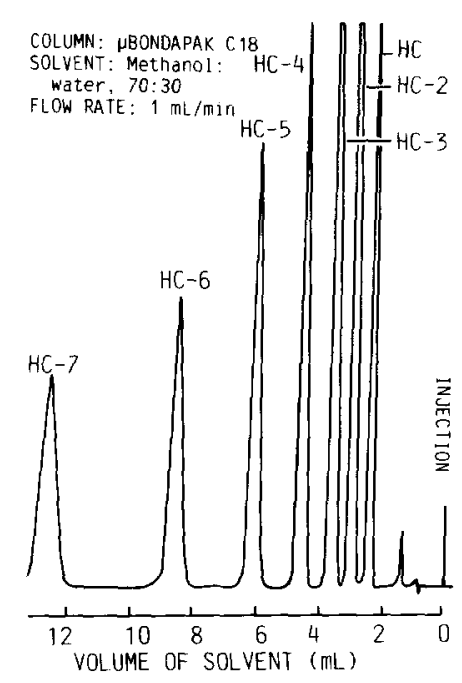

Fig. 1. Separation of hydrocortisone (HC) and its 21-n-alkyl esters (HC-2 to HC-7) on an HPLC chromatogram under the specified conditions (unequal concentrations).

methylene chloride and the extracts were collected in a $250-\mathrm{ml}$ round bottom flask. The combined extracts were then evaporated to dryness on the evaporator. The dried-phase residues were reconstituted with reagent grade methanol (usually 5-25 $\mathrm{ml}$ of methanol for the aqueous phase residue and 25-50 ml of methanol for the ether phase residue) and assayed by the following HPLC procedure (Hagen, 1979).

A Waters Associates solvent delivery system and absorbance detector were used with a reverse-phase high-efficiency liquid chromatography column. The mobile phase was a $70: 30 \mathrm{mix}-$ ture of reagent grade methanol and double-grade distilled water. The flow rate of the mobile phase was $1.0-1.5 \mathrm{ml} / \mathrm{min}$. The attenuation reference used was 0.1 , the injection volume was $50 \mu 1$ and the chart speed $0.25 \mathrm{~cm} / \mathrm{min}$. An Omniscribe recorder was used. The peak heights of the samples were compared to a concentration standard curve. The separation for hydrocortisone and its 21-n-alkyl esters on an HPLC chromatogram is shown in Fig. 1.

\section{Results and Discussion}

The logs of the obtained ether-water partition coefficients for hydrocortisone and the hydrocorti-
TABLE 2

Logs of ether - water partition coefficients $\left(\log k_{p}\right)$ of hydrocortisone and its 2I-n-alkyl esters obtained in this study and those of other authors

\begin{tabular}{ll}
\hline Compound & Log $k_{\mathrm{p}}$ \\
\hline Hydrocortisone & $0.15 \mathrm{a}$ \\
& $0.21 \mathrm{~b}$ \\
& $0.18 \mathrm{c}$ \\
& $0.11 \mathrm{~d}$ \\
Hydrocortisone-21-acetate & $1.43 \mathrm{a}$ \\
& $1.42 \mathrm{~b}$ \\
& $1.09 \mathrm{e}$ \\
& $1.11 \mathrm{~d}$ \\
Hydrocortisone-21-proprionate & $1.98 \mathrm{a}$ \\
Hydrocortisone-21-butyrate & $2.48 \mathrm{a}$ \\
& $2.37 \mathrm{~b}$ \\
Hydrocortisone-21-pentanoate & $2.96 \mathrm{a}$ \\
Hydrocortisone-21-hexanoate & $3.61 \mathrm{a}$ \\
& $3.56 \mathrm{~b}$ \\
Hydrocortisone-21-heptanoate & $4.14 \mathrm{a}$ \\
\hline
\end{tabular}

a, This study; b, Flynn (1971); c, Nathansohn et al. (1969); d, Katz and Shaikh (1965); e, Mantica et al. (1970).

sone 21-n-alkyl esters were listed together with those of other workers in Table 2.

All the ether-water partition coefficients obtained in this study are approximately the same as those obtained by other researchers.

When the logs of the ether-water partition coefficients were plotted as a function of alkyl

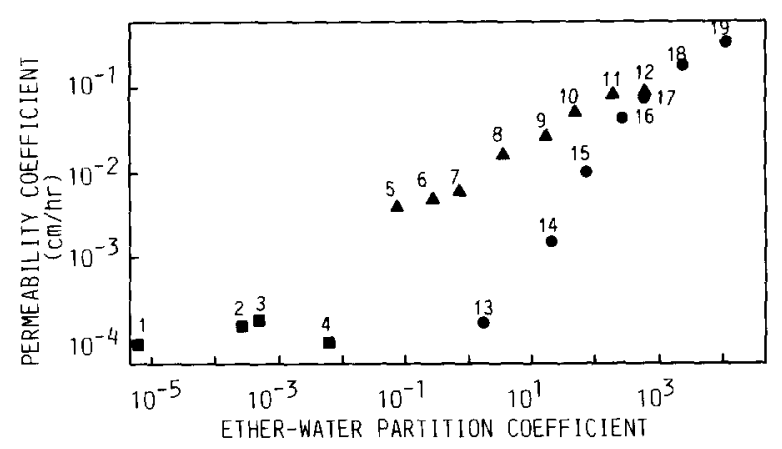

Fig. 2. The permeability coefficient $(\mathrm{cm} / \mathrm{h}$ ) for nude mouse skin as a function of the ether-water partition coefficient on a $\log -\log$ scale for the following compounds: (1) glucose, (2) urea, (3) glycerol, (4) thiourea, (5-12) $n$-alkanols, methanol to $n$-octanol, (13) hydrocortisone, (14-19) hydrocortisone 21-n-alkyl esters, -acetate to -heptanoate. 
chain length a linear line relationship is found and the slope of the plot is the $\pi$ value as defined by Fujita et al. (1964). The $\pi$ values in this study and for the data of Flynn (1971) are 0.542 and 0.536 with correlation coefficients of 0.9992 and 0.9985 , respectively. The excellent correlation found in this study indicates that the HPLC is a reliable method to determine the partition coefficients.

The ether-water partition coefficients of urea, thiourea, glycerol and glucose, a series of alkanols and hydrocortisone and its 21-n-alkyl esters and their permeability coefficients through nude mouse skin in vitro are listed in Table 1 . These values are plotted on a scale in Fig. 2.

The permeability coefficients of the hydrophilic compounds (glucose, urea, glycerol and thiourea) vary only from $1.0 \times 10^{-4} \mathrm{~cm} / \mathrm{h}$ while their ether-water partition coefficients vary from $9.0 \times$ $10^{-6}$ to $7.2 \times 10^{-3}$. There is no correlation between the partition coefficients and permeability coefficients for these compounds, which might indicate that permeation of hydrophilic compounds, with ether-water partition coefficients very much less than unity, does not depend upon the lipophilicity of the compound.

The mechanism of permeation of such hydrophilic compounds through nude mouse skin might therefore be mainly through the water-filled intercellular channels in the stratum corneum.

For the alkanols, the permeability coefficients seem to level off on going below a partition coefficient of 1 on the scale in Fig. 2. This corresponds to a lower limit permeability coefficient for the alkanol series of about $5.4 \times 10^{-3} \mathrm{~cm} / \mathrm{h}$.

It seems from Fig. 2 that there is a lower limit to permeability coefficients for nude mouse skin. This agrees with the suggestion made by Scheuplein and Blank (1973) that there is a finite lower limit of approximately $10^{-6} \mathrm{~cm} / \mathrm{h}$ for human skin permeability coefficients. There seems to be an upper limit at approximately $0.5 \mathrm{~cm} / \mathrm{h}$, which corresponds roughly to the permeability coefficients found for different compounds through the dermis only of nude mouse skin (Dürrheim, 1977; Smith, 1982; Ackermann et al., 1985).

It is significant to note that with the compounds mentioned in Fig. 2 the ether-water parti- tion coefficient changes with approximately 10 logarithmic orders while the permeability coefficient changes only 4 logarithmic orders. Thus $\pi$ for partitioning into the lipids of the stratum corneum may be the same for both the alkanols and the hydrocortisone ester series but the $\pi$ for permeation may deviate markedly from this value (Smith, 1982). This means that different diffusion pathways are not the only determinant of diffusivity and rate of permeation.

This discussion of the relation between ether-water partitioning and permeability was based on the permeability coefficients calculated from data obtained over the first $6 \mathrm{~h}$ of an experiment. But as mentioned earlier, the permeation of the hydrophilic compounds increased gradually as a function of time. This phenomenon was not mentioned in literature on the permeation of these compounds through oral mucosa (Siegel, 1981) or rabbit skin (Treherne, 1956); it is the topic of ongoing research in this laboratory.

\section{Conclusion}

The ether-water partition coefficients of hydrocortisone and its derivatives found in the literature were relatively reliable estimates easily and accurately complemented and verified in this work. When comparing the permeability coefficients to the ether-water partition coefficients of compounds ranging widely in hydrophobicity, no general pattern emerged. Thus the skin does not act as a simple lipoidal barrier with regard to compounds ranging much in hydrophobicity. The ether-water partition coefficients could therefore not be used to estimate the permeability coefficient of a compound through nude mouse skin in an infinite dose diffusion cell system.

Since a phenomenon of increasing permeability as a function of time was observed for urea, thiourea, glycerol, glucose, water and methanol by Ackermann (1983) and for hydrocortisone and hydrocortisone 21-n-alkyl esters (Smith, 1982 and Behl et al., 1984), one should be cautious about drawing extensive conclusions on the ether-water partitioning/percutaneous absorption relationships while there is uncertainty about the permeability coefficient that should be used. 


\section{Acknowledgements}

This research was sponsored by the CSIR, Smith \& Nephew, Noristan, Smith, Kline \& French and The Institute of Industrial Pharmacy and the Department of Pharmaceutics at the Potchefstroom University.

\section{References}

Ackermann, C., Percutaneous Absorption of Selected Hydrophilic Compounds - an In Vitro Study on Hairless Mouse Skin. Ph.D. Thesis, The Potchefstroom University for Christian Higher Education, 1983.

Ackermann, C., Flynn, G.L. and Van Wyk, C.J., Percutaneous absorption of urea. Int. J. Cosmet. Sci., 7 (1985) 251-264.

Behl, C.R., Flynn, G.L., Linn, E.E. and Smith, W.M., Percutaneous absorption of corticoids: age, site and skin sectioning influences on rates of permeation of hairless mouse skin by hydrocortisone. J. Pharm. Sci., 73 (1984) 1287-1290.

Dürrheim, H.H., 'n Biofisiese Model-Benadering vir die Ondersoek van Geneesmiddeloordrag deur die Vel. Ph.D. Thesis, The Potchefstroom University for Christian Higher Education, 1977.

Flynn, G.L., Structural approach to partitioning: estimation of steroid partition coefficients based upon molecular constitution. J. Pharm. Sci., 60 (1971) 345-353.

Fujita, T., Iwasa, J. and Hansch, C., A new substituent con- stant, derived from partition coefficients. J. Am. Chem. Soc., 86 (1964) 5175-5180.

Hagen, T.A., Physicochemical Study of Hydrocortisone and Hydrocortisone n-Alkyl-21-Esters, Ph.D. Thesis, The University of Michigan, 1979.

Hansch, C. and Leo, A., Substituent constants for correlation analysis in chemistry and biology, Wiley, New York, 1979.

Katz, M, and Shaikh, Z.I., Percutaneous corticosteroid absorption correlated to partition coefficient. J. Pharm. Sci., 54 (1965) 591-594.

Mantica, L., Ciceri, R., Cassagne, J. and M-Coriandoli, E., Prednacinolone, a new anti-inflammatory steroid. Arzneim. Forsch., 20 (1970) 109-110.

Nathansohn, G., Pasqualucci, C.R., Radaelli, P., Schiatti, P., Selca, D. and Winters, G., Steroids possessing nitrogen atoms. V(1) Some pharmacological and chemical-physical aspects of new class of active corticoids: (17a, 16a-d)oxazolino-steroids. Steroids, 13 (1969) 365-381.

Scheuplein, R.J. and Blank, I.H., Mechanism of percutaneous absorption. IV. Penetration of non-electrolytes (alcohols) from aqueous solutions and from pure liquids. J. Invest. Dermatol., 60 (1973) 286-295.

Siegel, I.A., Effect of chemical structure on non-electrolyte penetration of oral mucosa. J. Invest, Dermatol., 76 (1981) 137-140.

Smith, W.M., An Inquiry into the Mechanism of Percutaneous Absorption of Hydrocortisone and its $21-n-A l k y l$ Esters, Ph.D. Thesis, The University of Michigan, 1982.

Treherne, J.E., The permeability of skin to some non-electrolytes. J. Physiol. (Lond.), 133 (1956) 171-180. 